\title{
Nanohybrid and microfilled composite resin in Class II restoration of permanent molar teeth
}

\author{
Hasan Ali, Md. Joynal Abdin, Noor Jahan Akhter and Mozammal Hossain
}

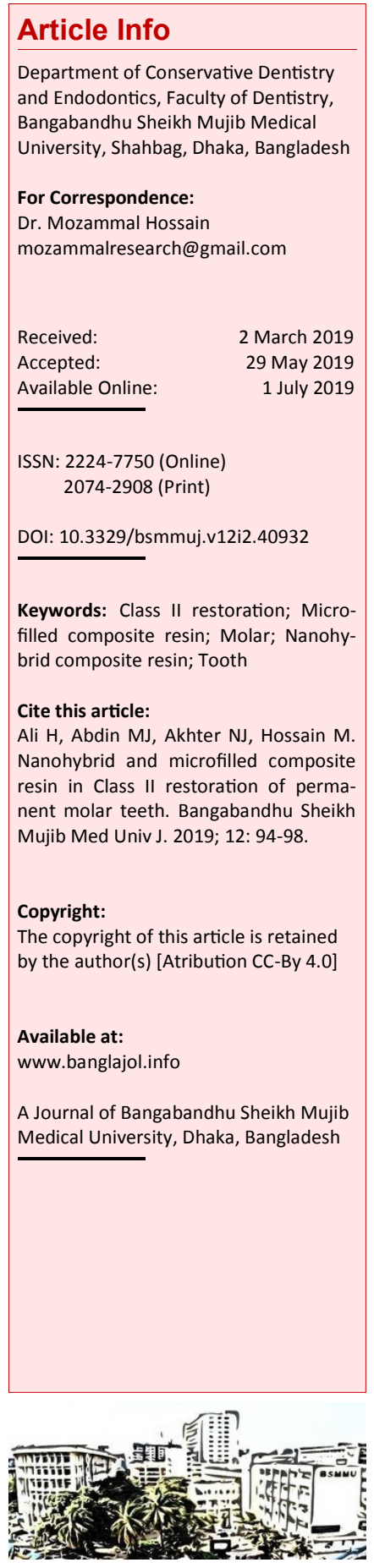

\section{Abstract}

The aim of this study was to compare the clinical performance of nanohybrid composite resin in Class II restorations placed with a one-step self-etch adhesive with that of microfilled composite resin of permanent posterior molar teeth. A total of 100 participants who received Class II restorations either with nanohybrid composite resin bonded with a single step self-etch adhesive or conventional microfilled composite bonded with a single step self-etch adhesive. All restorations were evaluated by using slightly modified USPHS criteria at baseline and after 3, 6 and 12 months. The results revealed that nanohybrid composite resin showed better clinical outcome than that of the conventional microfilled composite resin restorations in respect to retention and marginal adaptation at 12 months observation period. It can be concluded that nanohybrid is superior to conventional microfilled composite resin in respect to retention, and marginal adaptation of Class II restorations of permanent molar teeth.

\section{Introduction}

The development of composite resin have replaced the amalgam by improving the adhesive bonding system and its use in both anterior and posterior restorations has been expected in operative dentistry. 1 However, its use in larger posterior restorations is still controversial due to polymerization shrinkage and the adhesive interface is unable to resist the polymerization stresses in enamel free cavity margin.2,3 The large polymerization shrinkage results in improper sealing that causes microleakage, postoperative sensitivity, and recurrent caries. Furthermore, failure to achieve proper interproximal contact and incomplete cure of the composite resins in the deepest regions of a cavity are other challenges related to the direct composite restorations. 2

Recently, nanotechnology has been introduced in the dentistry which contains small particles of 0.1-100 nanometers ranges. 4 These small particles are favorable to obtain good wear resistance, easy polishable and better esthetics. $\underline{5}$ Firstly, developed nanofillers composite resin obtains high fracture toughness, better lasting polish, retention and aesthetics, and higher wear resistance.6,7 After that, modified ceramic resin composites ormocer have been introduced which contain multifunctional methacrylate alkoxysilanes for the synthesis of inorganicorganic copolymer composite materials. $\underline{8,9,10}$

The nanohybrid resin composite ceram $X$
(Dentsply-DeTrey, Germany) has been developed. In this system, the methacrylate modified silicon-dioxide-containing nanofiller (10 $\mathrm{nm}$ ) is used as substitute for the microfiller and conventional resin matrix which is replaced by a matrix full of highly dispersed methacrylate modified polysiloxane particles. $\underline{11}$ The ceramic particles are described as inorganic-organic hybrid particles where the inorganic siloxane part provides the strength and the organic methacrylic part makes the particles polymerisable with the resin matrix. Two recently published clinical evaluations showed clinical acceptable survival rates after two and four years for the nanohybrid ceram $X$ combined with etch-and-rinse adhesives. $\underline{10,12}$

The adhesive system has also been changed to one step self-etching adhesives system instead of traditional etch-and-rinse system. This adhesive system makes the bonding procedure by eliminating the risk of over etching and over drying, but the hybrid layer of the self-etching adhesive system is much thinner compared to the traditional etch-and-rinse system. The effectiveness of this system is favorable both in the laboratory and in short time evaluation.13, 14 Due to their high content of hydrolytical components and increased permeability of the hybrid layer, the bonds with self-etching adhesives system appear more vulnerable to degradation within the mouth. $\underline{15}$ However, a few clinical studies observed the clinical effectiveness of the nanohybrid resin composite with a 
one step self-etching adhesive system in the posterior cavities. Therefore, in the present study, the clinical outcome of Class II restorations performed with the nanohybrid composite resin bonded with a one step self-etching bonding system was compared to the conventional microfilled composite resin bonded with a one step self-etching bonding system.

\section{Materials and Methods}

This experimental clinical study was performed among the patients of Class II carious lesion from May 2017 to July 2018. A total of 100 teeth were divided into two groups and then 50 cavities that were restored with nanohybrid composite resin and the remaining 50 restored with conventional microfilled composite resin. Selection criteria were the patients attending the outpatient department who had moderate and shallow class II carious lesion (depth: 2-3 mm) of permanent molar teeth (Figure 1AE).

\section{Cavity preparation}

Operative procedures were performed under local anesthesia if necessary. Existing caries was removed under constant water cooling (Figure 1BF). The operative field was carefully isolated with cotton rolls and suction device. For all the Class II cavities, a thin metallic matrix was used and carefully wedging was performed with wooden wedges (Kerr/HaweNeos, Switzerland). The cavities were cleaned by a thorough full rinsing with water. Cavities were then divided into two groups and restored as follows:

Application of the one step self-etch adhesive was given according to the manufacturer's instructions. The resin composite was then applied in layers of maximally 2-3 $\mathrm{mm}$ depth (Figure 1CG). Every increment was light cured with a well-controlled LED light-unit (Smart lite, Dentsply/DeTrey) for at least $20 \mathrm{sec}$. The occlusion was checked and contouring with finishing diamond burs, the final polishing was performed with the Shofu polishing system (brownie) and finishing strips (GC finishing strips, Japan). The patient was recalled for clinical evaluations after 3, 6 and 12 months (Figure 1DH). Evaluation of retention was performed by visual inspection with dental mirror according to Ryge's criteria 16 as follows: (Alpha): Restoration was fully intact, (Bravo): Restoration was partially intact, (Charlie): Restoration was completely missing.

Evaluation of marginal adaptation: It was evaluated by visual inspection with explorer and dental mirror according to Ryge's criteria as follows: (Alpha): Explorer was not catched and no visible evidence of crevice, (Bravo): Explorer was penetrated along the margin or evidence of a crevice, (Charlie): Restoration was fractured, mobile, missing and the dentin/base was exposed.

Data of retention, marginal adaptation and compressive strength were collected and recorded in the data collection sheet individually. Statistical analysis of the results was done using a computerbased statistical software, SPSS 20.00 version (SPSS Inc. USA). For significance of difference chisquared test was performed. 95\% Confidence interval ( $p$ value $<0.05$ ) was followed for testing the level of significance.

\section{Results}

Nanohybrid composite resin restoration remained intact into the cavity at baseline and 3 observation period, then decreased gradually (Table I). Two restorations were partially intact and 2 were completely missing at 6 and 12 months. On the other hand, 3 conventional microfilled composite resin restorations was partially intact at 3 months followed by 6 partially intact and 2 completely missing at 6 months. When these restorations were examined at 12 months, 6 conventional microfilled composite resin were partially intact and 9 were completely missing. The differences between two groups were statistically significant $(p<0.05)$ at 12 months (Table I).

All restorations remained alpha rating at base line

\begin{tabular}{|c|c|c|c|c|c|c|c|}
\hline \multicolumn{8}{|c|}{ Table I } \\
\hline \multicolumn{8}{|c|}{ Number of retention and marginal adaptation and retention at different periods } \\
\hline \multirow[t]{2}{*}{ Evaluation } & \multirow[t]{2}{*}{ Score } & \multicolumn{3}{|c|}{ Nanohybrid $(n=50)$} & \multicolumn{3}{|c|}{ Microfilled $(n=50)$} \\
\hline & & 3 months & 6 months & 12 months & 3 months & 6 months & 12 months \\
\hline \multirow[t]{3}{*}{ Retention } & Alpha & 50 & 46 & 46 & 47 & 42 & 35 \\
\hline & Bravo & 0 & 2 & 2 & 3 & 6 & 6 \\
\hline & Charlie & 0 & 2 & 2 & 0 & 2 & 9 \\
\hline \multirow{3}{*}{$\begin{array}{l}\text { Marginal } \\
\text { adaptation }\end{array}$} & Alpha & 50 & 47 & 45 & 46 & 45 & 35 \\
\hline & Bravo & 0 & 0 & 2 & 4 & 5 & 11 \\
\hline & Charlie & 0 & 3 & 3 & 0 & 0 & 4 \\
\hline
\end{tabular}



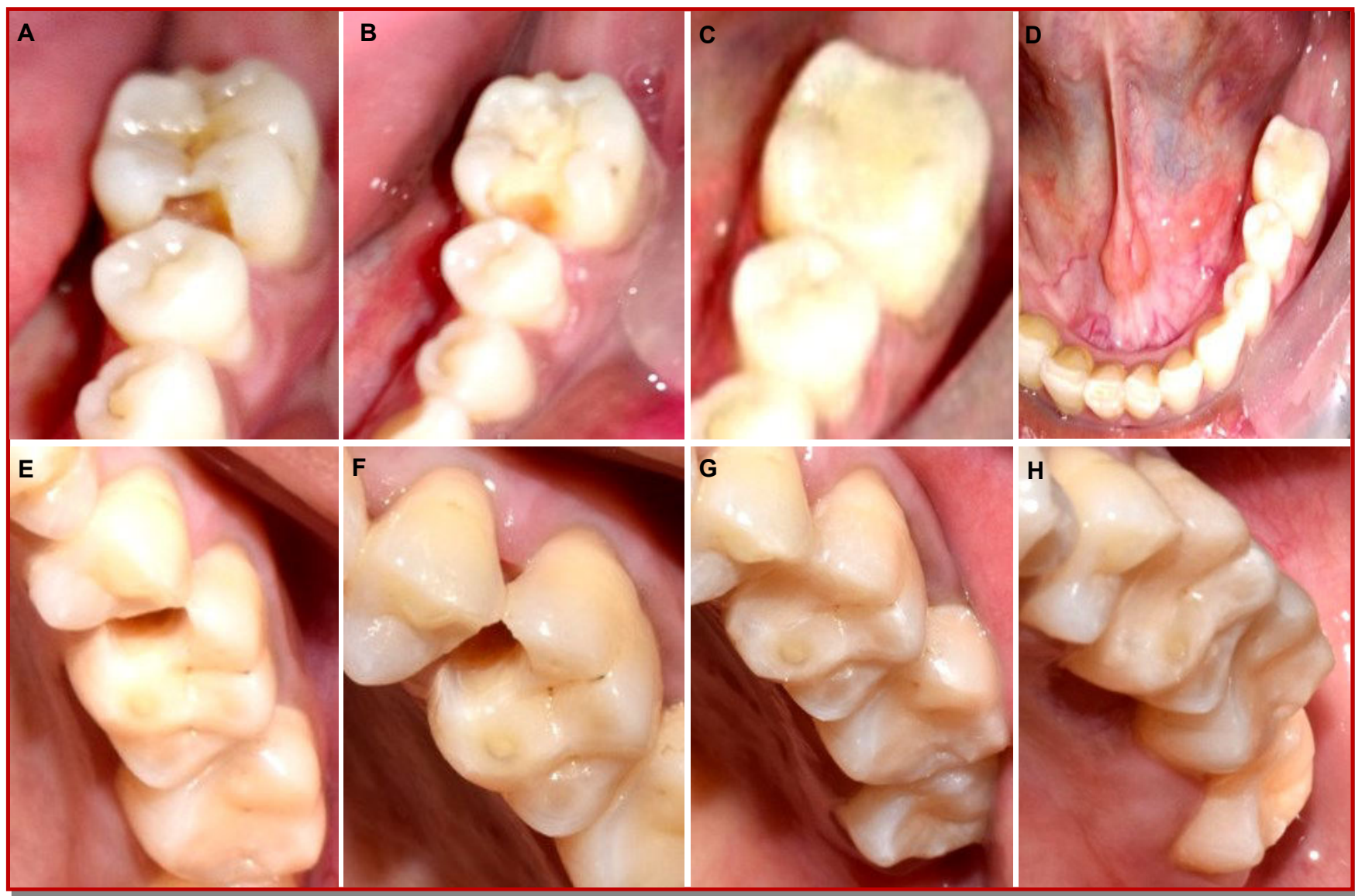

Figure 1: Representative photographs of restoration of nanohybrid composite (upper row) and microfilled composite resin (lower row). Class II carious lesion in the first molar tooth $(\mathrm{A}, \mathrm{E})$, removal of caries and cavity preparation $(\mathrm{B}, \mathrm{F})$, application of restorative material $(\mathrm{C}$, $\mathrm{G})$ and finally at 12 months $(\mathrm{D}, \mathrm{H})$ observation

and then gradually decreased (Table I). At 6 months observation period, 3 nanohybrid resin restorations were fractured and mobile followed by visible evidence of a crevice in 2 restoration and 3 restorations were fracture at 12 months observation periods. On the other hand, at 3 months, 4 conventional microfilled composite resin restorations demonstrated visible evidence of a crevice followed by at 6 months. When these restorations were examined at 12 months, 11 conventional microfilled composite resin showed evidence of a crevice along the margin and 4 revealed fracture and mobile. The differences between two groups at 3,6 and 12 months were statistically significant $(\mathrm{p}<0.05)$.

\section{Discussion}

In the present study, nanohybrid composite resin showed better clinical outcome than that of conventional microfilled composite resin restorations in Class II cavities. When these restorations were examined at 3, 6 and 12 months, it was found that most of the nanohybrid restorations showed acceptable retention and marginal adaptation. Further- more, the clinical outcome of nanohybrid restorations were also statistically significant than that of conventional microfilled composite resin restorations in respect to retention at 12 months observation period. The overall success rate in the retention of nanohybrid composite in the present study was $90 \%$ which was statistically significant than that of conventional microfilled (IvoclarVivadent's) composite resin restoration (success rate was $70.0 \%$ ). The results of marginal adaptation also revealed that marginal adaptation of nanohybrid composite resin was better than that of conventional microfilled composite resin.

The clinical outcome of the present study had similarities and dissimilarities with that of previous studies. In the present study, $2(4 \%)$ nanohybrid and $9(18 \%)$ showed loss of retention after one year clinical evaluation. Recently published clinical studies of nanohybrid and microfilled composites showed annual failure rates varying between $1.1 \%$ and $7.5 \%$ after $2-4$ years follow-up, respectively. $.10,13$, 17 However, the number of evaluated Class II restorations in some of previous studies was ranged between 9 and 18 restorations, to give significant clinical information. In contrast to some of the 
evaluations of the nanofilled resin composite, and other studies indicated that annual failures rates of different nanohybrid resin composites between 0 and $18 \%$. Furthermore, regarding the durability of the nanohybrid resin composites, Schirrmeister et al. (2006) $\underline{10}$ observed two failures of 24 Class II restorations after 4 years of nanohybrid resin composite. Monteiro et al. (2010) 12 found one failure of 30 restorations after 2 years. The results of the present in vivo study showed that $2(4 \%)$ nanohybrid and $9(18 \%)$ microfilled composite resin showed annual failure. The differences between the present and some of the previous studies may be due to the number and selected participants as several of these studies included low numbers of Class II restorations and selected participants. In the present study, 50 participants/teeth was used. This number was confirmed by a recently performed sample size estimated in a randomized intra individual comparison of resin composites. $\underline{22,23}$

However, in the present study, at 12 month observation period, $2(4.0 \%)$ nanohybrid restorations were partially intact. These restorations were not replaced and repaired by nanohybrid composite resin. Two $(4.0 \%)$ nanohybrid restorations revealed completely missing and replaced by a new restoration. On the other hand, 6 (12\%) microfilled restorations showed partially missing and $2(4 \%)$ reveled completely missing at 6 months followed by 6 were partially missing and 9 were completely missing at 12 months. The reasons of loss of retention in both nanohybrid and conventional micro-filled resin restorations were not clarified in the present study. But it may be due to loss of adhesion either by polymerization shrinkage or due to degradation of the adhesive itself. Other possible reasons of partial or complete loss of retention might be due to fracture or crack formation, inadequate elastic modulus and the flexibility of restorative material. Furthermore, the choice of adhesive system becomes important especially in large cavities when stress is higher as better retention could be achieved when restorative material is used along with bonding system. Furthermore, Peumans et al. (2007)똔 indicated that adhesives provide good clinical performance. Therefore, based on the present study and together with the previous studies it can be considered that loss of retention occur due to multi factorial etiology such as patient selection, location, occlusal stress, presence of sclerotic dentin, shape of the lesions, as well as on the properties of the materials used.

Regarding marginal adaptation, although nanohybrid composite resin restoration showed significantly better adaptation than that of conventional microfilled composite resin restoration, but at 6 months $3(6.0 \%)$ restoration showed fracture and mobile at 6 months followed by 2 visible crevice and 3 fracture and mobile at 12 months. Loss of marginal adaptation of these cases was due to chipping at margin of the restoration and they were not replaced but repaired with same material. A careful examination of these restorations revealed that all chipping occurred due to direct contact with opposing cusp. Direct composite restorations should not be placed in direct contact with opposing cusp. This is also supported by a previous study. $\underline{24}$

\section{Conclusion}

Nanohybrid is superior to conventional microfilled composite resin in respect to retention and marginal adaptation of Class II restorations of permanent molar teeth.

\section{Ethical Issue}

The research protocol was approved by the committee and permission for the study was taken from the Institutional Review Board of Bangabandhu Sheikh Mujib Medical University (BSMMU/2017/5505).

\section{Acknowledgement}

This work was supported by the Research Grant for Student, Bangabandhu Sheikh Mujib Medical University.

\section{References}

1. Sunnegärdh-Grönberg K, van Dijken JWV, Funegärd U, Lindberg A, Nilsson M. Selection of dental materials and longevity of replaced restorations in Public Dental Health clinics in northern Sweden. J Dent. 2009; 37: 673-78.

2. Loguercio AD, de Oliveira Bauer JR, Reis A, Grande RH. In vitro microleakage of packable composites in Class II restorations. Quintessence Int. 2004; 35: 29-34.

3. Thonemann B, Federlin M, Schmalz G, Grundler W. Total bonding vs selective bonding: Marginal adaptation of Class 2 composite restorations. Oper Dent. 1999; 24: 261-71.

4. Zakaria MA, Hossain M, Moral MA. Comparative efficacy of nanofilled and microfilled resin-modified glass ionomer as pits and fissure sealant in permanent molar teeth. Bangabandhu Sheikh Mujib Med Univ J. 2017; 10: 53-57.

5. Mitra SB, Wu D, Holmes BN. An application of nanotechnology in advanced dental materials. J Am Dent Assoc. 2003; 134: 1382-90.

6. Jung M, Sehr K, Klimek J. Surface texture of four nanofilled and one hybrid composite after finishing. Oper Dent. 2007; 32: 45-52. 
7. Korkmaz Y, Ozel E, Attar N, Aksoy G. The influence of one-step polishing systems on the surface roughness and microhardness of nanocomposites. Oper Dent. 2008; 33: 44-50.

8. Wolter $\mathrm{H}$, Storch $\mathrm{W}$, Ott $\mathrm{H}$. Ne inorganic/organic copolymers (ormocers) for dental applications. Mater Res Soc Symp Proc. 1994; 346: 143-49.

9. Shathi IJ, Hossain M, Gafur MA, Rana MS, Alam MS. A comparative study of microleakage between giomer and ormocer restoration in class I cavity of first permanent premolar teeth in vivo. Bangabandhu Sheikh Mujib Med Univ J. 2017; 10: 214-218.

10. Schirrmeister JF, Huber K, Hellwig E, Hahn P. Two -year evaluation of a new nano-ceramic restorative material. Clin Oral Investig. 2006; 10: 181-86.

11. Chen MH. Update on dental nano composites. J Dent Res. 2010; 89: 549-60.

12. Monteiro PM, Manso MC, Gavinha S, Melo P. Twoyear clinical evaluation of packable and nanostructured resin based composites placed with two techniques. J Am Dent Assoc. 2010; 141: 319-29.

13. van Dijken JWV, Sunnegärdh-Gro"nberg K, Sörensson E. Clinical bonding of a single-step selfetching adhesive in noncarious cervical lesions. J Adhes Dent. 2007; 9: 241-43.

14. Peumans M, De Munck J, Van Landuyt K, Lambrechts P, Van Meerbeek B. Five-year clinical effectiveness of a two-step self-etching adhesive. J Adhes Dent. 2007; 9: 7-10.

15. Tay FR, King NM, Chan KM, Pashley DH. How can nanoleakage occur in self-etching adhesive systems that demineralize and infiltrate simultaneously? J Adhes Dent. 2002; 4: 255-69.

16. Cvar JF, Ryge G. Reprint of criteria for the clinical evaluation of dental restorative materials. Clin Oral
Investig. 2005; 9: 215-32.

17. Manhart J, Chen HY, Hickel R. Three-year results of a randomized controlled clinical trial of the posterior composite QuiXfil in class I and II cavities. Clin Oral Investig. 2009; 13: 301-07.

18. Cetin AR, Unlu N. One-year clinical evaluation of direct nanofilled and indirect composite restorations in posterior teeth. Dent Mater J. 2009; 28: 62026.

19. Dresch W, Volpato S, Gomes JC, Ribeiro NR, Reis A, Loguercio AD. Clinical evaluation of a nanofilled composite in posterior teeth: 12-month results. Oper Dent. 2006; 31: 409-17.

20. Palaniappan S, Bharadwaj D, Mattar DL, Peumans M, Van Meerbeek B, Lambrechts P. Three-year randomized clinical trial to evaluate the clinical performance and wear of a nanocomposite versus a hybrid composite. Dent Mater. 2009; 25: 1302-14.

21. Mahmoud SH, El-Embaby AE, AbdAllah AM, Hamama HH. Two-year clinical evaluation of ormocer, nanohybrid and nanofill composite restorative systems in posterior teeth. J Adhes Dent. 2008; 10 : 315-22

22. Hickel R, Roulet JF, Bayne S, Heintze SD, Mjör IA, Peters M, Rousson V, Randall R, Schmalz G, Tyas M, Vanherle G. Recommendations for conducting controlled clinical studies of dental restorative materials. Clin Oral Invest. 2007; 11: 5-33.

23. Shi L, Wang $X$, Zhao Q, Zhang $Y$, Zhang L, Ren $Y$, Chen $Z$. Evaluation of packable and conventional hybrid resin composites in Class I restorations: Three-year results of a randomized, double-blind and controlled clinical trial. Oper Dent. 2010; 35: 1119.

24. Condon JR, Ferracane JL. Factors effecting dental composite wear in vitro. J Biomed Mater Res. 1997; 38: 303-13. 